Original Research Paper

\title{
A New Approach to Model Concentrating PV Cells Under Non-Uniform Illumination
}

\author{
${ }^{1}$ Hang Zhou, ${ }^{1}$ Yuehong Su, ${ }^{2}$ Gang Pei, ${ }^{2}$ Yunyun Wang and ${ }^{3}$ Tiezhou WU \\ ${ }^{1}$ Department of Architecture and Built Environment, \\ Institute of Sustainable Energy Technology, University of Nottingham, University Park, NG7 2RD, UK \\ ${ }^{2}$ Department of Thermal Science and Energy Engineering, \\ University of Science and Technology of China, 96 Jinzhai Road, Hefei City, 230026, China \\ ${ }^{3}$ Hubei Collaborative Innovation Center for High-efficiency Utilization of Solar Energy, \\ Hubei University of Technology, Wuhan, 430068, China
}

Article history

Received: 02-10-2014

Revised: 22-01-2015

Accepted: 13-07-2017

Corresponding Author:

Yuehong $\mathrm{Su}$

Department of Architecture and

Built Environment, University

of Nottingham, University

Park, NG7 2RD, UK

Gang Pei

Department of Thermal Science and Energy Engineering,

University of Science and

Technology of China, 96

Jinzhai Road, Hefei City,

230026, China

E-mail: peigang@ustc.edu.cn yuehong.su@nottingham.ac.uk

\begin{abstract}
Concentrating PV (CPV) cells are often designed optimally depending on solar concentrator characteristics and operating conditions to ensure the best system performance. Before reaching a PV cell, solar radiation may experience some optical losses caused by the different physical phenomena occurring in a solar concentrator. A particular issue with the CPV technology is the non-uniformity of the concentrated radiation, which will cause power dissipation and reduce the overall efficiency of the PV cell. Considering this issue and understanding of its effect is significant in PV cell design and optimization. This paper presents a new approach for modeling PV cell under non-uniform illumination condition, in which a PV cell is represent by an equivalent array of cell splits. The main advantage of this approach is the possibility to express each cell split voltage as an explicit function of the current by using the Lambert-W function. The output characteristics are simulated and analyzed using proposed simulation approach built in MATLAB/Simulink platform. Through the analysis of the results, a comprehensive expression of the PV cell under non-uniform illumination could be present.
\end{abstract}

Keywords: CPC, CPV, Cell Splits, Array, Non-uniform illumination, MATLAB/Simulink, Lambert-W Function

\section{Introduction}

PV cell is the key element in the photovoltaic system design. Concentrating Photovoltaics (CPV) offers the best use of the silicon material for manufacturing of PV cells and has the potential to increase the electrical output power by several times while using the same amount of silicon PV cells.

A issue with CPV technology is the non-uniformity of illumination distribution on PV cell surface, which will cause power dissipations and reduce the overall efficiency of the system. Although the use of solar concentrators can amplify the incident solar radiation on the PV cells by several times, it still has the non-uniform issue. This nonuniformity could happen on a single piece PV cell or to a module consist of several PV cells. In the case of nonuniform illumination, there is excessive illumination on some regions of the PV cell and others are less illuminated. The regions being excessively illuminated generate huge current and get heated up. This reduces the electrical output of the PV cell and the generation of cross current may cause physical damage to the cells.
Non-uniform illumination leads a decrease in PV cell performance since higher light intensities occur near the cell center in comparison with edges. This increases the power losses in the cell front grid and its front surface diffused regions. Vishnoi et al. (1989) clearly described the combination effect of non-uniform illumination and surface resistance on the performance of PV cell.

The concentrator geometry and optics play an important role to determine the flux that incident on PV cells. Figure 1 gives an example of flux distribution from a mirror Compound Parabolic Concentrator (CPC) (Guiqiang et al., 2013; Vishnoi et al., 1989; Su et al., 2012). It could be seen that the non-uniform illumination is significantly appears in the receiver of CPC system. The CPC is designed to collect solar radiation for an extended period. When the incident angle is changing through the day, its optical feature will let the illumination profile become non-uniformed. The optical analysis can tell each flux and its distribution. However, the way to analyze the concentrating PV cell electrical performance under nonuniform illumination condition still more details. 
This paper proposes an approach in which a low concentrating PV cell could be considered equivalent to an array of cell splits connected in parallel. Each split has different illumination profile to model the nonuniform illumination condition. The electrical performances for each split and their parallel-connected array will be simulated by a designed program in MATLAB/Simulink. Different illumination distributions are simulated to give a comprehensive analysis of the low concentrating PV cell's photovoltaic performance under non-uniform illumination condition.

\section{Experimental Validation of Using Parallel- Connected PV Cell Splits to Restore Original PV Cell Performance}

The electrical characteristics of silicon solar cell are influenced by the size changing. Based on the fact, a reasonable hypothesis has been proposed to analyze the concentrated cell performance under non-uniform illumination condition. We divide a single piece of cell into several splits to fit the illumination profile, where each split has separate irradiance value and cell temperature. Ideally, the integrated cell splits group should restore the same output performance as a single piece solar cell.

Single piece silicon PV cell is common material that used in PV module design, the manufacturers normally provide some basic cell electrical characteristics such as short-circuit current, open-circuit voltage and maximum power. One objective of this experiment is to use the given electrical characteristics of original PV cell to deduce the performance of the cutout splits of PV cell.

The short-circuit current is the current through the PV cell when the voltage across the cell is zero.

The short-circuit current is due to the generation and collection of light-generated carriers and it directly depends on the light intensity. It is common to list it as short-circuit current density in unit such as $\mathrm{A} / \mathrm{m}^{2}$, which gives the current a proportional relationship with cell surface area.

The voltage characteristic is mainly depend on the material properties of a PV cell. Open-circuit voltage is then a measure of the amount of recombination in the cell. Depending on the material, PV cells of different types have typical value for the open-circuit voltage and have no obvious changing with cell surface area. In the parallel-connected circuit, the same voltage is applicable to all circuit components and the total current is the sum of the currents through the individual components, in accordance with Kirchhoff's current law.

An indoor experiment was set up at the University of Nottingham to verify the proposed hypothesis. In this experiment, a single piece mono-crystalline silicon PV cell was cut into four equally splits as shown in Fig. 2 and connected in parallel as shown in Fig. 3. The electrical characteristics and dimension for the original single PV cell are list in Table 1.
The incident light is supplied by a halogen lamp with an average irradiance level at $1000 \mathrm{~W} / \mathrm{m}^{2}$. The electrical outputs were measured and recorded with a RS PV analyzer (ISM-490). The PV cell temperature was measured with thermocouples and displayed by a multimeter. The cell temperature for splits was around $25^{\circ} \mathrm{C}$ at the beginning of the test.

According to the experiment results, the I-V curves for the four splits are plotted in Fig. 4, which proves each split gives almost equally outputs under the same environment condition. The differences are mainly due to the temperature varying, since the testing cells' temperature increased rapidly under the light source. Like other semiconductor devices, PV cell is very sensitive to temperature varying. The increasing cell temperature reduces the band gap of PV cells. It will also lead to an increase in short-circuit current and decrease in opencircuit voltage. The error from manually cut also has some effect on the testing results.

Figure 5 gives the integral $\mathrm{I}-\mathrm{V}$ curves for both the original single cell and the parallel-connected cell splits group. As shown in Fig. 5, the I-V curve for parallelconnected cell splits group matching well with the curve for the original cell. It is confirmed that the parallel splits group can restore the same power output as the original single cell. From the results, the reliability of the proposed hypothesis has been verified.

\section{Modelling of PV Cell}

The simulation begins with the modeling of PV cell. The most common methods to carry out this electrical simulation is to divide the cell into smaller sub-circuits to represent different parts of the PV cell and then model every sub-circuit by an electrical circuit as one diode with distributed diode effect. The resistance in the PV cell leads to a voltage drop across the cell, which produces different current densities. By taking consideration of this phenomena, the current from each row of the cells unit will flow to the contact grid bar, where adds to the current contribution from other rows. The voltage drops due to the resistance along the row of cells unit are additive and the voltage drop along the contact bar are additive. A simplified representation of the electrical circuit model for a single PV cell is shown in Fig. 6.

The electrical circuit model consists of a photocurrent source, a diode, a shunt resistor expressing a leakage current and series resistor describing an internal resistance to the current flow. In link with the equivalent circuit, the PV cell output current is represented by following equation:

$I=I_{p h}-I_{o}\left[\exp \left(\frac{q}{k T n}\left(V+I R_{s}\right)\right)-1\right]-\frac{V+I R_{s}}{R_{s h}}$

By using this equation, the PV cell could be modelled. However, different approaches have been adopted by different researchers to analyse the effects of non-uniformity. 

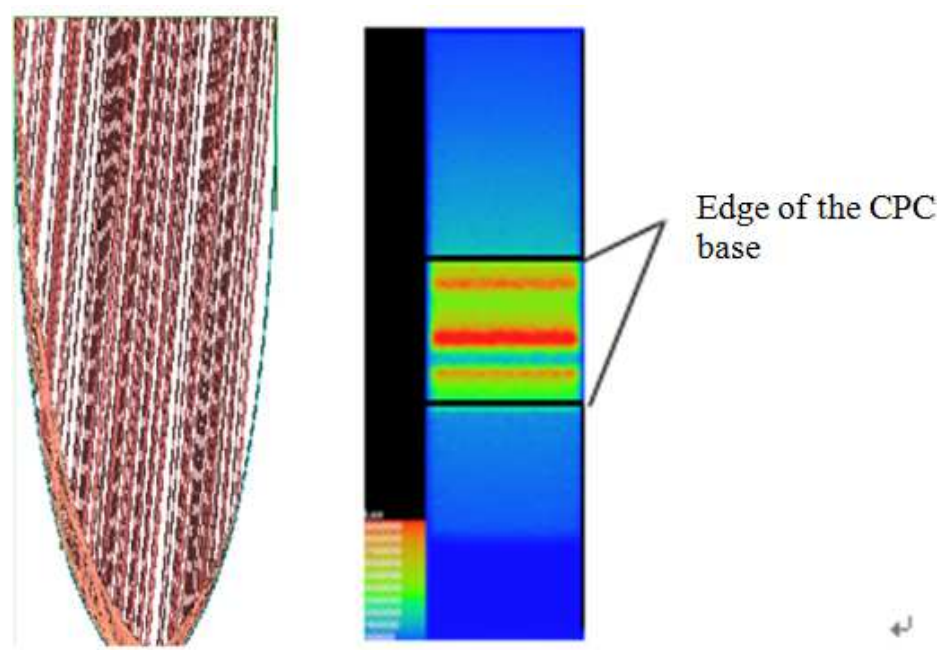

Fig. 1. Flux distribution on the base of a mirror CPC

Table 1. Data sheet for testing cell

\begin{tabular}{ll}
\hline Test PV cell & Mono-crystalline silicon PV cell \\
\hline Dimension & 15.5 by $15.5 \mathrm{~cm}$ \\
Short-circuit current & $2.52 \mathrm{~A}$ \\
Open-circuit voltage & $0.58 \mathrm{~V}$ \\
Average power & $0.93 \mathrm{~W}$ \\
\hline
\end{tabular}

González-Longatt (2005) proposed a model, which ignore the parallel resistor and simplify the equation into three parameters current equation. The calculation in that method is relative simple with low accuracy. Therefore, Tsai (2009) suggested to use differential equations at both short-circuit point and open-circuit point to form a closure equation group related to cell's five parameters. However, the I-V equation which has been quoted is a non-linear equation and it requires additional iteration process to get the solution. In the iteration process, the results could lose accuracy due to parameters changing to large extent. De Soto et al. (2006) proposed a model by using manufactory data to predict the PV module performance, but it requires special calculation software to implement and assuming the series resistance does change with temperature. In fact, the PV module operating temperature strongly influences the series resistance. This study proposed a method which is similar as Tsai (2009) method, but using some mathematical technique to change the current non-linear equation to algebraic equation.

Theoretically, the output characteristics of PV cell is solved by calculating cell's five parameters and substituting into the I-V equation. Those five parameters include diode ideal factor n, reverse saturation current $I_{o}$, photo-current $I_{p h}$, series resistance $R_{s}$, parallel resistance $R_{s h}$. However, the expression of current is a non-linear equation which cannot be solved directly. Therefore, to obtain the required cell's five parameters, it is necessary to propose the relevant closed set of equations. By using some mathematical techniques, it is possible to change the current non-linear equation to algebraic equation and get following closed set of equations:

$$
\left.\begin{array}{rl}
V_{m}\left(R_{s h o}-R_{s o}\right)\left[V_{m}-R_{s h o}\left(I_{s c}-I_{m}\right)\right] \\
R_{s}= & \begin{array}{l}
R_{s o}\left(V_{m}-R_{s h o} I_{m}\right)\left(V_{o c}-R_{s h o} I_{s c}\right) \\
I_{m}\left(R_{s h o}-R_{s o}\right)\left[V_{m}-R_{s h o}\left(I_{s c}-I_{m}\right)\right] \\
\\
+\left(V_{m}-R_{s h o} I_{m}\right)\left(V_{o c}-R_{s h o} I_{s c}\right)
\end{array} \\
R_{s h}= & R_{s h o}-R_{s} I_{p h}=I_{s c}\left(1+\frac{R_{s}}{R_{s h}}\right) \\
n= & \frac{\left(R_{s}-R_{s h o}\right)\left(V_{o c}-R_{s h o} I_{s c}\right)}{V_{t h}\left(R_{s h o}-R_{s o}\right)} \\
I_{o}= & \frac{I_{p h}-\frac{V_{o c}}{R_{s h}}}{\exp \left(\frac{V_{o c}}{n V_{t h}}\right)-1}
\end{array}\right\}
$$

Based on the mathematical expression for each parameter and accounting to one cell's $I_{s c}, V_{o c}, V_{m}, I_{m}$, $\left.\frac{d V}{d I}\right|_{v=0}=-R_{s h o},\left.\frac{d V}{d I}\right|_{v=0}=-R_{s o}$, the five parameters including $R_{s}, R_{s h}, I_{p h}, I_{o}$ and icould be solved. The PV cell's final output characteristics can be given by substituting five parameters into the I-V equation.

\section{Parameter Calculation for Different Irradiance and Temperature}

The output power from PV cell is varying with the changing of the incident irradiance, cell operation temperature and load. The manufacturers usually only provide the I-V curve under Standard Testing Condition. By considering the non-uniformity of environmental conditions, a prediction of module performance under different conditions is necessary. The output characteristics of PV cell is related to environment factors and cell's parameters. Based on the past research, the relationship between module parameters and environment factors are listed as follow. 


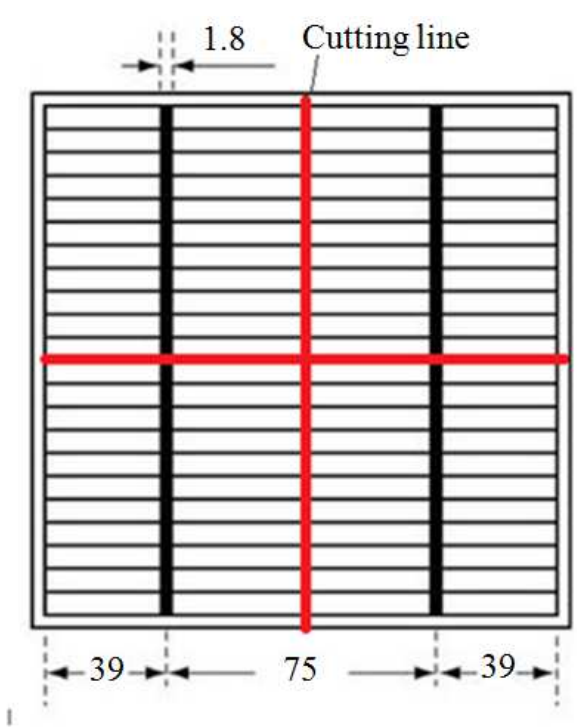

Fig. 2. Legend of PV cell

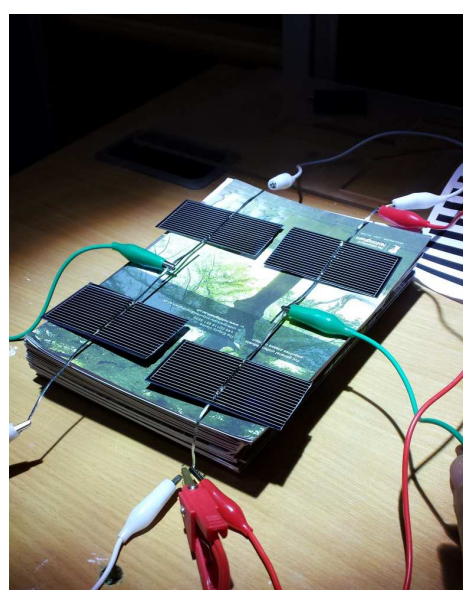

Fig. 3. Parallel connected splits

\section{Photo-Current}

Zhai (2008) described the photo-current $I_{p h}$ using following equation:

$$
I_{p h}=\frac{S}{S_{r e f}}\left(\mathrm{I}_{p h, r e f}+\alpha_{1 s c}\left(\mathrm{~T}-\mathrm{T}_{r e f}\right)\right)
$$

\section{Reverse Saturation Current}

Messenger and Ventre (2004) used the diode equation and described the reverse saturation current as follow:

$$
\begin{aligned}
& \frac{I_{o}}{I_{o, \text { ref }}}=\left(\frac{T}{T_{r e f}}\right)^{3} \exp \left(\frac{1}{k}\left(\frac{E_{g, \text { Tref }}}{T_{r e f}}-\frac{E_{g, T}}{T}\right)\right) \\
& \frac{E_{g}}{E_{g, \text { ref }}}=1-0.0002677\left(\mathrm{~T}^{\mathrm{T}} \mathrm{T}_{r e f}\right)
\end{aligned}
$$

\section{Series Resistance}

The series resistance could be described as a function related to cell temperature. The resistance value is increasing with the temperature rise:

$$
\frac{R_{s}}{R_{s, \text { ref }}}=\frac{T}{T_{r e f}}\left(1-\beta \ln \frac{S}{S_{r e f}}\right)
$$

\section{Shunt Resistance}

Schroder (1998) proposed the parallel resistance is inversely proportional to the short-circuit current at very low irradiation level:

$$
\begin{aligned}
& \frac{R_{s h}}{R_{s h, r e f}}=\frac{I_{s c, r e f}}{I_{s c}} \\
& I_{s c}=I_{s c, r e f} \frac{S}{S_{r e f}}\left[1+\alpha_{1 s c}\left(\mathrm{~T}-\mathrm{T}_{r e f}\right)\right]
\end{aligned}
$$

\section{Modelling of Parallel-Connected PV Cell Splits}

The general current model of PV cell is an implicit function and transcendental equation about $V$. It is not easy to decouple $I$ and $V$ in the function. The introducing of Lambert-W function is the solution to solve the decoupling problem with $I$ and $V$. By using Lambert-W function, it could transform the current equation into the following equations:

$$
I=\frac{R_{s h}\left(I_{p h}+I_{o}\right)-V}{R_{s}+R_{s h}}-\frac{n V_{t h}}{R_{s}} W(X)
$$

The main advantage of Equation 7 is the possibility to express each cell split's voltage as an explicit function of the current by using the Lambert-W function, which enables the prediction of the output characteristic of cell groups under any environment condition.

Based on the above experiment, a solar cell is equivalent to an array of cell splits connected in parallel. Assuming $N$ splits parallel-connected, the new voltage output $V$ is formed by voltage from each split. The total output current is the sum of the current from all cell splits in the array. The parallel group output current is given as:

$$
\begin{gathered}
I=\sum_{i=1}^{N} I_{i}=\sum \frac{\left(I_{p h 1}+I_{o 1}\right) R_{s h 1}-V}{R_{s 1}+R_{s h 1}}-N \frac{n_{1} V_{t h}}{R_{s 1}} W \\
\left\{\frac{I_{o 1} R_{s h 1} R_{s 1} \exp \left[\frac{R_{s h 1}\left(I_{p h 1} R_{s 1}+I_{o 1} R_{s 1}+V\right)}{n_{1} V_{t h}\left(R_{s 1}+R_{s h 1}\right)}\right]}{n_{1} V_{t h}\left(R_{s 1}+R_{s h 1}\right)}\right\}
\end{gathered}
$$




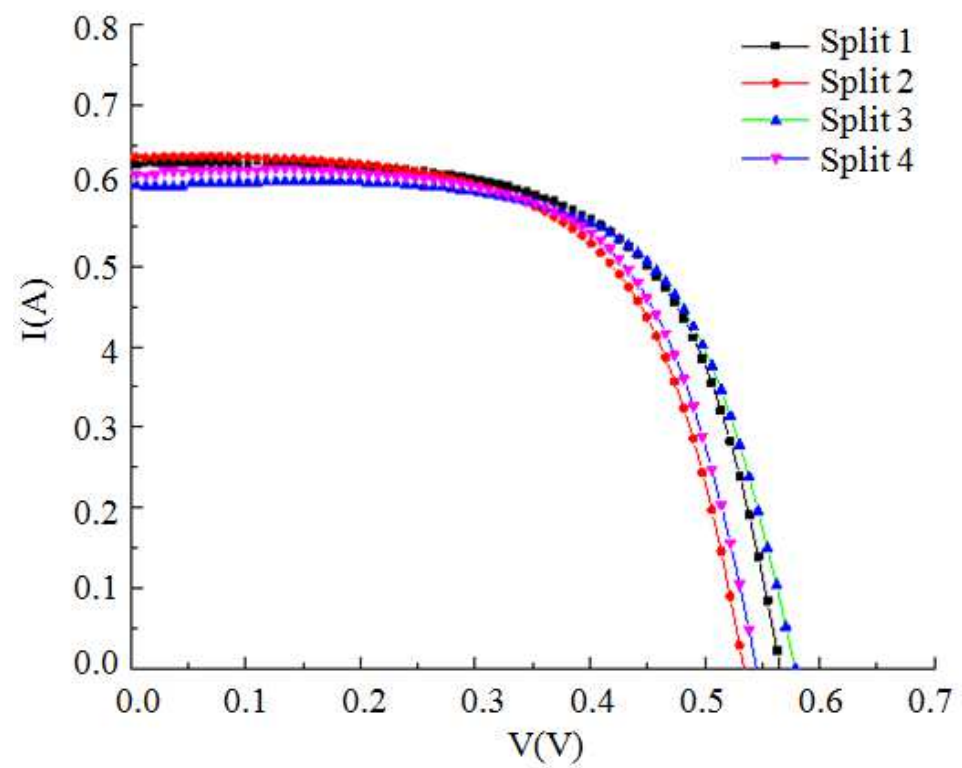

Fig. 4. I-V for four cell splits

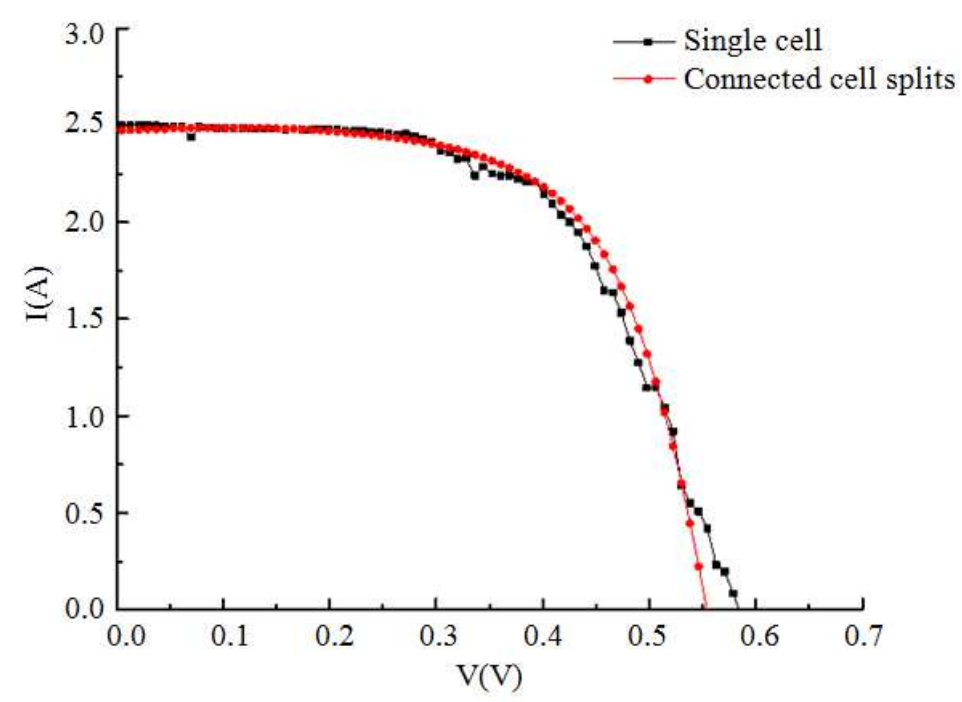

Fig. 5. I-V for original single cell and parallel-connected splits under the same illumination

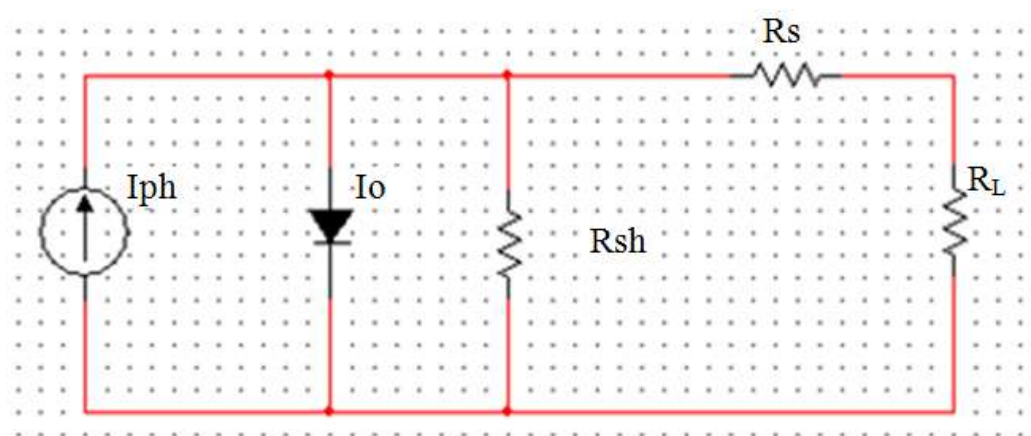

Fig. 6. Equivalent circuit for a single PV cell 
Because each split has different parameters according to the cell condition, it is difficult to give out the analytical expression of the new characteristic parameters with the connection, but they could be deducing from different working points, such as.

At short circuit point, substituting $V=0$ into Equation 8, gives:

$$
I_{s C}=\sum\left[\frac{R_{s h 1}\left(I_{p h 1}+I_{o 1}\right)}{R_{s 1}+R_{s h 1}}-\frac{n_{1} V_{t h}}{R_{s h}} W\left(X_{s c 1}\right)\right]
$$

At open circuit point, substituting $I=0$ into Equation 8, gives:

$$
0=\sum\left[\frac{R_{s h 1}\left(I_{p h 1}+I_{o 1}\right)-V_{O C}}{R_{s 1}+R_{s h 1}}-\frac{n_{1} V_{t h}}{R_{s 1}} W\left(X_{O C 1}\right)\right]
$$

At maximum power point:

$$
I_{M}=\sum\left[\frac{\left(I_{p h 1} I_{o 1}\right) R_{s h 1}-V_{M}}{R_{s 1}+R_{s h 1}}-\frac{n_{1} V_{t h}}{R_{s h}} W\left(Y_{M 1}\right)\right]
$$

Differentiating Equation 8 gives:

$$
\begin{aligned}
& \frac{d I_{1}}{d V_{1}}=-\frac{1}{R_{s 1}}+\frac{R_{s h 1}}{R_{s 1}\left(R_{s}+R_{s h 1}\right)\left(1+W\left(X_{1}\right)\right)} \\
& \frac{d I}{d V}=\sum_{i=1}^{N} \frac{d I_{1}}{d V}=\sum_{i=1}^{N} \frac{d I_{1}}{d V_{1}}
\end{aligned}
$$

At short circuit point:

$$
\begin{aligned}
& \left.\frac{d I}{d V}\right|_{I=I_{S C}}=\left.\sum_{i=1}^{N} \frac{d I_{1}}{d V_{1}}\right|_{I I I S C} \\
& =\sum_{i=1}^{N}\left[-\frac{1}{R_{s 1}}+\frac{R_{s h 1}}{R_{s 1}\left(R_{s}+R_{s h 1}\right)\left(1+W\left(X_{S C 1}\right)\right)}\right]
\end{aligned}
$$

At open circuit point:

$$
\begin{aligned}
& \left.\frac{d I}{d V}\right|_{V-V_{O C}}=\left.\sum_{i=1}^{N} \frac{d I_{1}}{d V_{1}}\right|_{V=V_{O C}} \\
& =\sum_{i=1}^{N}\left[-\frac{1}{R_{s 1}}+\frac{R_{s h 1}}{R_{s 1}\left(R_{s}+R_{s h 1}\right)\left(1+W\left(X_{O C 1}\right)\right)}\right] \\
& \left.\frac{d V}{d I}\right|_{I=I_{S C}}=\left.\frac{1}{\left.\frac{d I}{d V}\right|_{I=I_{S C}}} \frac{d V}{d I}\right|_{V-V_{O C}}=\frac{1}{\left.\frac{d I}{d V}\right|_{V-V_{O C}}}
\end{aligned}
$$

The requiring parameters for parallel-connected cell splits are calculated by above steps, where the simulation program is based on those equations. The general solving procedure is present in Fig. 7.

\section{Modelling of Low Concentrating PV Cell Under Non-Uniform Illumination}

An example low concentrating PV cell in a CPC design was chosen to be a testing object to discuss the photovoltaic performance of solar cell under non-uniform illumination condition. This concentrating PV cell has the dimension of $1^{*} 20 \mathrm{~cm}$, as seen in Fig. 8. Some of the basic electrical characteristics for the cell are listed in Table 2.

In the simulation process, the low concentrating cell was assumed to be formed by an array of 10 cell splits connected in parallel. Theses splits have been numbered consecutively from right (No. 1) to left (No. 10). According to the theory and experiment validation in the previous sections, the current characteristics of the small splits is $1 / 10$ of the original PV cell value and given in Table 3 .

By using those data as the reference, the five parameters for the original single cell and splits were calculated through the designed program. The results are listed in Table 4 and 5.

In this simulation study, the non-uniform illumination profile was obtained by giving different irradiance values for each split. Table 6 presents six different illumination distribution profiles, which all have an average illumination at $1000 \mathrm{~W} / \mathrm{m}^{2}$. Through Distribution 1 to 6 , the degree of non-uniformity has been increased systematically. To give more accurate analysis on the low concentrating cell behavior under non-uniform illumination. It is assumed that the cell operating temperature for each split and original cell stay constant at $25^{\circ} \mathrm{C}$. The single piece PV cell has one integral input for both irradiance and temperature.

Table 7 lists simulation results for each cell parameters at different distributions. Since the average illumination and temperature stay constant, some parameters like short-circuit current $I_{s c}$, photocurrent $I_{p h}$ and open-circuit voltage $V_{o c}$ have no obvious changes. However, there is a significant difference in Fill Factor (FF) for different distributions. The fill factor determines the maximum power from a PV cell and it is defined as the ratio of maximum power from the PV cell to the product of $V_{o c}$ and $I_{s c}$. The fill factor is calculated by using formula:

$F F=\frac{V_{m} I_{m}}{V_{o c} I_{s c}}$

The peak point of the curve is the maximum power point ( $\mathrm{Pm})$ and it is a measure of the "squareness" of the curve. Based on simulation results, the I-V curves for each illumination distribution are plotted in Fig. 9. It clearly shows the maximum power point is shifting to the left as the increasing of the degree of non-uniformity. That means the output power from the cell is decreased. As the degree of non-uniformity increase, the cell maximum power could drop by $20.7 \%$. This phenomenon is mainly caused by the increase of $\mathrm{PV}$ cell internal series resistance. According to the simulation results in Table 7, the series resistance $R_{s}$ is almost double in the worst situation. 
Define the value of Isc Voc Im Vm Rsho Rso of the cell
Subsitute into five-parameters solving closure equations
Output Iph Io n Rs

Rsh and use as reference
Produce the output for module

\author{
Substitute into \\ Lambert W \\ represented \\ fuctions
}

Calculate parameters for module: Isc Voc Im Vm Rsho Rso<smiles>C1C2CC1C2</smiles>

Calculate new Iph Io $n$ Rs Rsh correspond to cell condition

Fig. 7. Logic flow chart of simulation program

Fig. 8. Concentrating PV cell

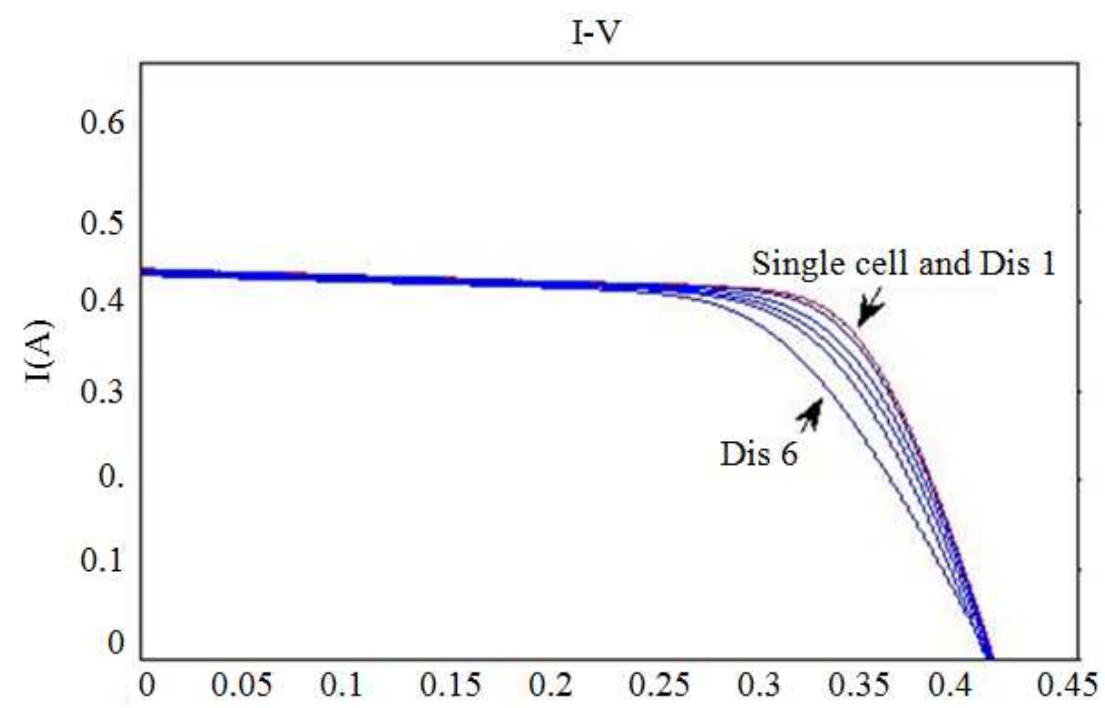

Fig. 9. I-V for different illumination distributions

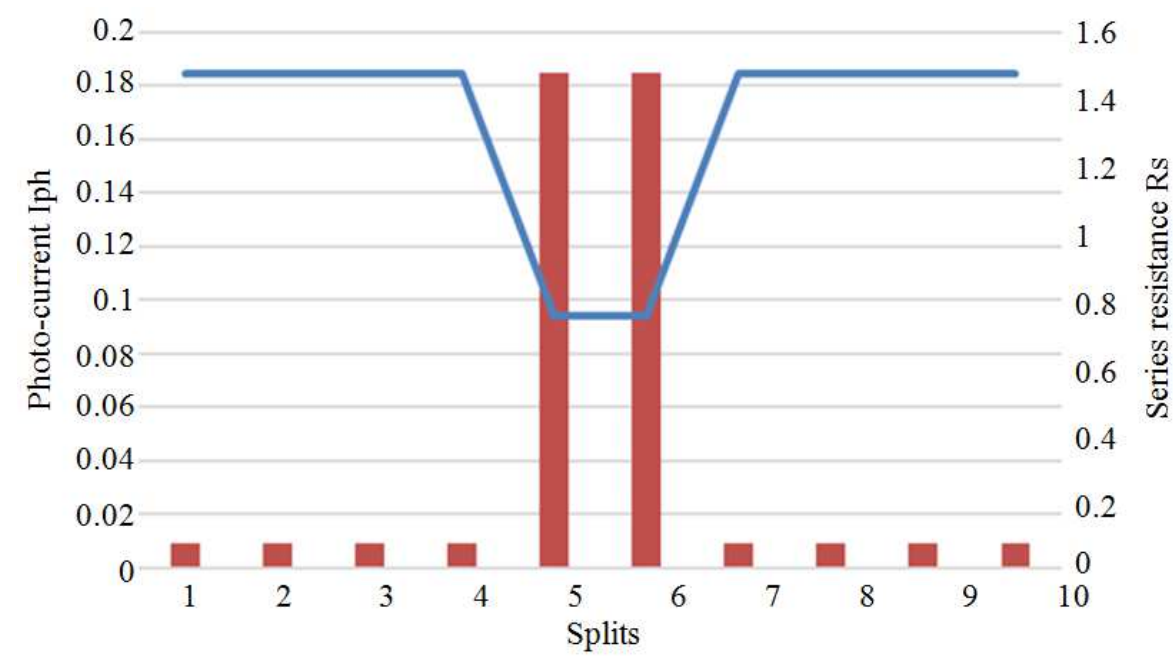

Fig. 10. Parameter numerical distribution for Distribution 5 
Table 2. Reference data for single concentrating PV cell

\section{Parameter}

Short-circuit current $I_{s c}$

Table 3. Reference data for single cell split

\section{Parameter}

Short-circuit current $I_{s c}$

Open-circuit voltage $V_{o c}$

Maximum power point current $I_{m p p}$

Maximum power point voltage $V_{m p p}$

$R_{\text {sho }}$

Table 4. Five parameters for single concentrating PV cell

\section{Parameter}

\section{Photo-current $I_{p h}$}

Reverse saturation current $I_{o}$

Series resistance $R_{s}$

Shunt resistance $R_{s h}$

Table 5. Five parameters for single cell split

Parameter

Photo-current $I_{p h}$

Reverse saturation current $I_{o}$

Series resistance $R_{s}$

Shunt resistance $R_{\text {sh }}$

Ideal factor

Table 6. Illumination distribution profile

\begin{tabular}{|c|c|c|c|c|c|c|c|c|c|c|c|}
\hline 1 & 2 & 3 & 4 & 5 & 6 & 7 & 8 & 9 & 10 & \multicolumn{2}{|c|}{ Average $\mathrm{S} \mathrm{W} / \mathrm{m}^{2}$} \\
\hline 1000 & 1000 & 1000 & 1000 & 1000 & 1000 & 1000 & 1000 & 1000 & 1000 & 1000 & Distribution 1 \\
\hline 800 & 800 & 800 & 800 & 1800 & 1800 & 800 & 800 & 800 & 800 & 1000 & Distribution 2 \\
\hline 600 & 600 & 600 & 600 & 2600 & 2600 & 600 & 600 & 600 & 600 & 1000 & Distribution 3 \\
\hline 400 & 400 & 400 & 400 & 3400 & 3400 & 400 & 400 & 400 & 400 & 1000 & Distribution 4 \\
\hline 200 & 200 & 200 & 200 & 4200 & 4200 & 200 & 200 & 200 & 200 & 1000 & Distribution 5 \\
\hline 1 & 1 & 1 & 1 & 4996 & 4996 & 1 & 1 & 1 & 1 & 1000 & Distribution 6 \\
\hline
\end{tabular}

Table 7. Simulation results for different illumination distributions

\begin{tabular}{llllllllll}
\hline & $\mathrm{I}_{\mathrm{sc}}(\mathrm{A})$ & $\mathrm{I}_{\mathrm{ph}}(\mathrm{A})$ & $\mathrm{V}_{\mathrm{oc}}(\mathrm{V})$ & $\mathrm{P}_{\mathrm{m}}(\mathrm{W})$ & $\mathrm{V}_{\mathrm{m}}(\mathrm{V})$ & $\mathrm{I}_{\mathrm{m}}(\mathrm{A})$ & $\mathrm{R}_{\mathrm{s}}(\Omega)$ & $\mathrm{R}_{\mathrm{sh}}(\Omega)$ & $\mathrm{FF}$ \\
\hline Sing cell & 0.437 & 0.440 & 0.429 & 0.135 & 0.341 & 0.397 & 0.109 & 15.004 & 0.72 \\
Distribution 1 & 0.437 & 0.440 & 0.429 & 0.135 & 0.341 & 0.396 & 0.109 & 15.004 & 0.72 \\
Distribution 2 & 0.437 & 0.440 & 0.429 & 0.133 & 0.338 & 0.394 & 0.110 & 15.017 & 0.71 \\
Distribution 3 & 0.436 & 0.439 & 0.428 & 0.128 & 0.329 & 0.388 & 0.115 & 15.054 & 0.68 \\
Distribution 4 & 0.434 & 0.437 & 0.427 & 0.120 & 0.315 & 0.383 & 0.120 & 15.102 & 0.65 \\
Distribution 5 & 0.432 & 0.436 & 0.425 & 0.113 & 0.298 & 0.380 & 0.120 & 15.154 & 0.62 \\
Distribution 6 & 0.430 & 0.435 & 0.427 & 0.107 & 0.283 & 0.377 & 0.183 & 15.176 & 0.58 \\
\hline
\end{tabular}

Figure 10 provides more details about the relationship between irradiance and series resistance. The data were obtained based on Distribution 5. It has found that the photocurrent is directly proportional to the irradiance and the splits near the sides have much less irradiance than the center part, which leads to a higher series resistance values, referring to Equation 5. This confirms the dropping of fill-factor is mainly from series resistance rising in the less illuminated splits. 


\section{Conclusion}

The contribution of this paper is proposing a simulation approach for concentrating PV cell, which considers the PV cell as a parallel-connected array of several cell splits and analyzes its electrical performance under non-uniform illumination. It provides a useful basis for the study of the concentrating PV cell under the changing weather condition. The experiment in the first section provides the evidence of the reliability of the proposed approach. The simulation takes concern of several illumination profiles and models the low concentrating PV cell's photovoltaic performance according to the different degrees of non-uniformity. From those results, it can analyze the concentrating PV cell in more details and provide an accurate prediction of its performance under non-uniform illumination. In summary, the non-uniform distribution illumination would reduce the efficiency of PV cell performance by the dropping in the maximum power point. As the degree of non-uniformity increases, the cell's efficiency could drop by $20.7 \%$. Under the constant temperature condition, the main factor to describe this phenomenon is the rising of PV cell internal series resistance.

The simulation model in this study could be an array modelling, which is mostly based on the mathematical expression. In the real application, PV cell is not only containing silicon film but also finger and connection bar. It would be interesting to use Finite Element Method to simulate the PV cell as an integrated physical entity to investigate some of the physical characteristics such as current density distribution on the PV cell surface. The concentrating PV cell is usually very small in the geometry and it is hard to simulate the assumed nonuniform distribution with the common light source, but it is encouraging to verify the presented approach through experiment with suitable equipment.

\section{Acknowledgement}

Thanks to European Commission for a Marie Curie Fellowship grant (PIIF-GA-2009-253945). Some work of this paper was presented at the 9th International Green Energy Conference in Tianjin, China, 2014.

\section{Funding Information}

This work was conducted with the support of a Marie Curie Fellowship grant (PIIF-GA-2009-253945)

\section{Author's Contributions}

Hang Zhou: Has carried the experimental and modelling work and made the draft manuscript.

Yuehong Su: Has supervised this study and revised the manuscript.
Gang Pei: Has jointly supervised this study.

Yunyun Wang: Has helped with use of LambertW function.

Tiezhou Wu: Has helped to check the equations for modelling of PV cell.

\section{Ethics}

There is no ethical issue that may rise with publication of this manuscript.

\section{References}

De Soto, W., S.A. Klein and W.A. Beckman, 2006. Improvement and validation of a model for photovoltaic array performance. Solar Energy, 80: 78-88.

González-Longatt, F., 2005. Model of photovoltaic module in Matlab. Universidad Nacional Experimental Politécnica, Carretera Nacional Maracay-Mariara.

Guiqiang, L., G Pei, Y. Su, J. Ji and S.B. Riffat, 2013. Experiment and simulation study on the flux distribution of lens-walled compound parabolic concentrator compared with mirror compound parabolic concentrator. Enery, 58: 398-403.

Messenger, R.A. and J. Ventre, 2004. Photovoltaic Systems Engineering. 2nd Edn., CRC Press LLC, Boca Raton, FL.

Schroder, D.K., 1998. Semiconductor Material and Device Characterization. 2nd Edn., John Wiley and Sons Inc., New York.

Su, Y., G. Pei, S.B. Riffat and H. Huang, 2012. Radiance/Pmap simulation of a novel lens-walled compound parabolic concentrator (lens-walled CPC). Energy Proc., 14: 572-577.

Tsai, H.L., 2009. Irradiation-oriented model of photovoltaic module using Matlab/Simulink, Electrical Engineering Department, Da-Yeh University.

Vishnoi, A., R. Gopal, R. Dwivedi and S.K. Srivastava, 1989. Combined effect of no uniform illumination and surface resistance on the performance of a solar cell. Int. J. Electron., 66: 755-774.

Zhai, Z., 2008. Prediction of PV module output characteristics under any irradiance level. University of Science and Technology of China.

\section{Nomenclature}

$S \quad$ Solar irradiation on $\mathrm{PV}$ cell, $\mathrm{W} / \mathrm{m}^{2}$

$I \quad \mathrm{PV}$ cell/module current, A

$V \quad \mathrm{PV}$ cell/module voltage, $\mathrm{V}$

$q \quad$ Electronic charge, $1.602176 \mathrm{e}-19 \mathrm{C}$

$k \quad$ Boltzmann constant, $1.38065 \mathrm{e}-23 \mathrm{~J} / \mathrm{K}$

$n$ Diode ideal factor

$T \quad$ Temperature, ${ }^{\circ} \mathrm{C}$

$I_{p h} \quad$ Photocurrent, A

$I_{o} \quad$ Reverse saturation current, A 
Hang Zhou et al. / Energy Research Journal 2017, 8 (2): 37.46 DOI: 10.3844/erjsp.2017.37.46

$R_{s} \quad$ Series resistance, $\Omega$

$R_{s h} \quad$ Shunt resistance, $\Omega$

$R_{\text {sho }} \quad$ Slope of I-V at $I=I_{s c}$

$R_{s o} \quad$ Slope of I-V at $V=V_{o c}$

Eg Band-gap energy, eV

$\alpha \quad$ Temperature coefficient $\%, \mathrm{~A} /{ }^{\circ} \mathrm{C}$

$\beta \quad$ Material constant

$I_{m p p} \quad$ Maximum power point current, A

$V_{m p p} \quad$ Maximum power point voltage, $\mathrm{V}$

FF Fill factor 